\title{
MOLECULAR IDENTIFICATION AND PATHOGENIC VARIATION OF FUSARIUM SPECIES ISOLATED FROM VANILLA PLANIFOLIA IN PAPANTLA MEXICO
}

\author{
Jacel Adame-García ${ }^{1,2}$, Raúl Rodríguez-Guerra33 , Lourdes Georgina Iglesias-Andreu², \\ José María Ramos-Prado ${ }^{4}$ and Mauricio Luna-Rodrícuez ${ }^{5,6}$ \\ 'Instituto Tecnológico de Úrsulo Galván, Tecnológico Nacional de México. Úrsulo Galván, Veracruz. México \\ ${ }^{2}$ Instituto de Biotecnología y Ecología Aplicada, Universidad Veracruzana. Xalapa, Veracruz, México \\ ${ }^{3}$ Instituto Nacional de Investigaciones Forestales, Agrícolas y Pecuarias, Campo Experimental General Terán. \\ General Terán, Nuevo León. México \\ ${ }^{4}$ Centro de EcoAlfabetización y Diálogo de Saberes, Universidad Veracruzana. Xalapa, Veracruz, México \\ ${ }^{5}$ Laboratorio de Alta Tecnología de Xalapa, Universidad Veracruzana. Xalapa, Veracruz, México \\ ${ }^{6}$ Corresponding author: mluna@uv.mx
}

\begin{abstract}
Although vanilla originated from Mexico and an important pathogen for this plant is Fusarium oxysporum f. sp. vanilla, studies concerning their association are limited. Previous reports on agents that cause root and stem rot in vanilla clearly indicate that Fusarium species are associated with this disease. During 2009 and 2010 in Papantla, which is the greatest vanilla-producing region of Mexico, the fungus was isolated from vanilla roots and stems that showed symptoms of the disease. From 189 isolates of Fusarium, 11 morphologically different colonies were selected to verify the species of each colony by microscopic observation of their morphological characteristics when cultivated on SNA and PDA media and by amplifying and sequencing their ITS regions. The detected species corresponded to F. proliferatum, Fusarium sp., F. oxysporum f. sp. vanillae (which was the most numerous and most pathogenic to vanilla stems and leaves), an undetermined species of Fusarium, and F. proliferatum, which showed no evidence of producing disease symptoms.
\end{abstract}

Key words: Fusarium oxysporum f. sp. vanillae, pathogenicity, stem rot, vanilla

Resumen: A pesar de que México es centro de origen de la vainilla y de la importancia que representa Fusarium oxysporum f. sp. vanillae como patógeno para este cultivo, los estudios al respecto son limitados. Reportes previos sobre los agentes causales de la pudrición de tallo y raíz en vainilla, indican que especies de Fusarium están asociadas con la enfermedad. En Papantla, región mexicana de mayor producción de este cultivo, se obtuvieron aislamientos fúngicos a partir de tallo y raíz de vainilla con síntomas de la enfermedad durante 2009 y 2010. De un total de 189 aislamientos de Fusarium, se seleccionaron 11 colonias morfológicamente distintas para verificar la especie a la que correspondían mediante la observación microscópica de sus características morfológicas a partir de organismos crecidos en medio SNA y PDA, así como la amplificación y secuenciación de la región ITS. Las especies detectadas correspondieron a: F. proliferatum, Fusarium sp. y F. oxysporum f. sp. vanillae, donde esta última, fue la más numerosa y patogénica en tallos y hojas de vainilla, seguida de la especie de Fusarium no determinada y finalmente F. proliferatum, que no desarrolló síntomas de la enfermedad.

Palabras clave: Fusarium oxysporum f. sp. vanillae, patogenicidad, pudrición de tallo, vainilla

$\mathrm{C}$ ultivated vanilla has a narrow genetic base because it has been extensively cloned (Minoo et al., 2008), which implies that the species is susceptible to epidemics that greatly impact production via a large number of diseases. Among these diseases are stem and root rot caused by Fusarium oxy- sporum, wilting due to Phytophthora spp., rust caused by Calospora vanillae Massee, rot caused by Sclerotium sp., and necrosis or anthracnose produced by Colletotrichum gloeosporioides (Penz.) Sacc. (Bhai and Thomas, 2000; Summerell et al., 2003; Guzman, 2004; Talubnak and Soytong, 2010). 
Among these diseases, special attention has been given to the rotting of stems and roots caused by Fusarium, which was initially suggested as being produced by $F$. batatis Wr. var. vanillae (Tucker, 1927). Alconero and Santiago (1969) later indicated that F. oxysporum f. sp. vanillae was the true cause of this disease.

Studies carried out in Indonesia by Pinaria et al. (2010) led to the isolation of 12 species of Fusarium that were associated with this disease (F. decemcellulare, F. fujikuroi, $F$. graminearum, $F$. mangiferae, $F$. napiforme, $F$. oxysporum, $F$. polyphialidicum, $F$. proliferatum, $F$. pseudocircinatum, $F$. semitectum, $F$. solani, and $F$. subglutinans), in which $F$. oxysporum has been proven to be the most common species, followed by $F$. solani and $F$. semitectum. These findings have been confirmed in other vanilla-producing regions, and Fusarium oxysporum f. sp. vanillae has been identified as the principal agent responsible for the disease (Tombe et al., 1993; Bhai and Kumar, 2008; Pinaria et al., 2010).

Despite stem and root rot constituting most of the disease symptoms that affect vanilla production and having been responsible for huge economic losses over the last decades in countries such as Indonesia (Pinaria et al., 2010), this issue has not been sufficiently studied in Mexico, and little concerning the biology of Fusarium oxysporum f. sp. vanillae has been investigated.

Thus, the objectives of this research were: (i) to identify the Fusarium species isolated from vanilla in Papantla Mexico, (ii) to determine the dominant Fusarium species associated with stem and root rot of vanilla, (iii) to amplify and sequence the ITS regions of the species to confirm the morphological identification, and to identify unknown isolates.

\section{Materials and methods}

Collection and isolation of Fusarium spp. During 2009 and 2010, vanilla roots, stems, and leaves with symptoms of rot (suggesting the presence of Fusarium) were collected from Vanilla planifolia plants cultivated on a system of orange trees, as standards, in the region of Papantla, Veracruz $\left(20^{\circ}\right.$ $21^{\prime} 47.57^{\prime \prime} \mathrm{N}$ and $97^{\circ} 30^{\prime} 39.06$ " W). The pathogens were isolated from the collected material in the laboratory.

The samples were washed with running water and disinfected with a $2 \%$ solution of sodium hypochlorite for $1 \mathrm{~min}$ and then washed twice with sterile distilled water. Two fragments of tissue $(\sim 5 \times 5 \mathrm{~mm})$ from the area near the damaged region were removed and placed in Petri dishes containing potato-dextrose-agar culture medium (PDA) (DIBICO) or Czapek dox medium (Bioxon).

The Petri dishes were placed in a microbiological incubator (BG Mod E-71) at $25 \pm 1{ }^{\circ} \mathrm{C}$, and the samples were examined after 24, 48, and $72 \mathrm{~h}$ under a Carl Zeiss, Axiostar microscope to observe the formation of mycelia and to transfer tips and groups of hyphae to new dishes containing PDA. The colonies that developed were observed again under the microscope to identify isolates that corresponded to the Fusarium genus according to Leslie and Summerell (2006).

From these isolates, a suspension of spores was obtained, and $200 \mu \mathrm{L}$ of this suspension was dispersed over Spezieller Nährstoffarmer culture medium (SNA: $1.0 \mathrm{~g} \mathrm{KH}_{2} \mathrm{PO}_{4} ; 1.0 \mathrm{~g}$ $\mathrm{KNO}_{3} ; 0.5 \mathrm{~g} \mathrm{MgSO}_{4} .7 \mathrm{H}_{2} \mathrm{O} ; 0.5 \mathrm{~g} \mathrm{KCl} ; 0.5 \mathrm{~g}$ glucose, $0.2 \mathrm{~g}$ sucrose and $20.0 \mathrm{~g}$ agar in $1 \mathrm{~L}$ of distilled $\mathrm{H}_{2} \mathrm{O}$ ). After $24 \mathrm{~h}$, single germinated conidia were transferred to the same culture medium and incubated for $24 \mathrm{~h}$ at $25 \pm 1{ }^{\circ} \mathrm{C}$. The single spore cultures were maintained in an active state and used for species identification.

Morphological and molecular analysis of Fusarium spp. The morphological identification of the single spore cultures was performed according to Montiel-González et al. (2005). To achieve this, a $100-\mu \mathrm{L}$ aliquot of a suspension of conidia $\left(10^{6} \mathrm{~mL}^{-1}\right)$ was dispersed over Petri dishes containing SNA medium. After $24 \mathrm{~h}$, three germinated spores were obtained, which were then individually transferred to Petri dishes $(100 \times 15 \mathrm{~mm})$ containing SNA, PDA or CLA (Carnation Leaf-Piece Agar).

After 14 days, the microscopic characteristics of the colonies were observed. Taxonomic characterization was based on the descriptions indicated by Nelson et al. (1983) and Leslie and Summerell (2006). The colonies that developed on the PDA plates were incubated for 14 days to observe their color. The isolates were then stored in PDA and SNA media with mineral oil at $4{ }^{\circ} \mathrm{C}$ (Lima, 1991).

Molecular identification of the isolates required total DNA extraction according to Cheng and Jiang (2006). For this process, $1.0 \mathrm{~g}$ of mycelia was extracted after ten days of development on PDA at $25{ }^{\circ} \mathrm{C}$. To grind the mycelia, $400 \mu \mathrm{L}$ of TE buffer (10 mM Tris/HCl, $1 \mathrm{mM}$ EDTA, pH 8.0) and $200 \mu \mathrm{L}$ of phenol-saturated Tris (2 M, pH 8.0) were added. The solution was then transferred to $1.5-\mathrm{mL}$ tubes and centrifuged at $8,000 \mathrm{~g}$ for $5 \mathrm{~min}$ to separate the aqueous phase from the organic phase. Subsequently, $160 \mu \mathrm{L}$ of the supernatant was transferred to a $1.5-\mathrm{mL}$ sterile tube, and $40 \mu \mathrm{L}$ of TE buffer and $100 \mu \mathrm{L}$ of chloroform were added.

The solution was centrifuged for $5 \mathrm{~min}$ at $13,000 \mathrm{~g}$, and the lysate was purified with chloroform twice until a white interface was achieved. Following this process, $160 \mu \mathrm{L}$ of the supernatant was transferred to a $1.5-\mathrm{mL}$ tube, $40 \mu \mathrm{L}$ of TE and $5 \mu \mathrm{L}$ of RNase $\left(10 \mathrm{mg} \mathrm{mL}^{-1}\right)$ were added, and the solution was incubated at $37^{\circ} \mathrm{C}$ for $10 \mathrm{~min}$. Finally, $100 \mu \mathrm{L}$ of chloroform was added, and the solution was mixed by inversion and centrifuged for $5 \mathrm{~min}$ at $13,000 \mathrm{~g}$, after which $150 \mu \mathrm{L}$ of supernatant was transferred to a sterile $1.5-\mathrm{mL}$ tube. The aqueous phase contained the purified DNA.

The integrity of the DNA was evaluated by electrophoresis in $0.8 \%$ agarose gels (TBE $0.5 \mathrm{X}$ ) in a horizontal chamber (CONSORT) at $100 \mathrm{~V}$. The gels were stained in $100 \mathrm{~mL}$ TBE $1 \mathrm{X}$ solution containing $2 \mu \mathrm{L}$ of ethidium bromide (10 
$\mathrm{mg} \mathrm{mL}-1$ ) for $20 \mathrm{~min}$ and then visualized using a photo-documentation (MicroBis) system.

Internal transcribed spacers 1 and 2 (ITS1 and ITS2) were amplified following the procedure established by Vilgalys and Hester (1990) using the oligonucleotides BMB-CR (5'-GCTTAAGTTCAGCGGGT-3') and LR0 (5'-GCTTAAGTTCAGCGGGT-3'). Amplification was carried out in a reaction mixture of $25 \mu \mathrm{L}$ containing 10X PCR buffer, 2.5 $\mathrm{mM} \mathrm{MgCl}, 1 \mathrm{U}$ Taq DNA pol, $0.25 \mathrm{mM}$ dNTPs, $25 \mathrm{pM}$ of each initiator (BMB-CR and LR0), and 50-100 ng genomic DNA.

The process was performed in a thermal cycler (Mastercycler personal Eppendorf) using the following program: 30 cycles of denaturation at $94^{\circ} \mathrm{C}$ for $1 \mathrm{~min}$, annealing at $50{ }^{\circ} \mathrm{C}$ for $45 \mathrm{sec}$ and extension at $72^{\circ} \mathrm{C}$ for one min followed by a final extension at $72{ }^{\circ} \mathrm{C}$ for seven min (Vilgalys and Hester, 1990).

The PCR products were purified using a ChargeSwitch ${ }^{\circledR}$ - Pro PCR Clean-up Kit (Invitrogen) following the manufacturer's instructions and then sequenced at the Instituto de Biotecnología, Universidad Nacional Autónoma de México (UNAM) using an Applied Biosystems Sequencer (model 391) and employing the BMB-CR oligonucleotide.

The sequence data were edited using BioEdit version 7.0.5.3 (Hall, 1999) and analyzed via the Basic Local Alignment Search Tool (BLAST) system (GenBank, National Center for Biotechnology Information (NCBI) and FUSARIUM-ID (Geiser et al., 2004).

Phylogenetic and molecular analyses were conducted using MEGA version 5 (Tamura et al., 2011) with the Maximum Parsimony (MP) and Maximum Likelihood methods. The MP tree was obtained using the Close-Neighbor-Interchange algorithm (Nei and Kumar, 2000), and the Maximum Likelihood method was based on the Tamura-Nei model (Tamura and Nei, 1993). The bootstrap consensus tree was inferred from 10,000 replicates (Felsenstein, 1985).

Sequences from Fusarium species that were related to vanilla and reported by Pinaria et al. (2010) were included as species that, according to BLAST, were related to the ITS sequences; these species included the following: $F$. sporotrichioides ATCC 34914 (AB587025.1), F. semitectum IP2239 (AF130380.1), F. oxysporum f. sp. vanillae DL-1-1 (AY383320.1), F. oxysporum f. sp. vanillae ML-1-1 (AY387700.1), F. subglutinans ATCC 38016 (AY898251.1), F. nygamai ATCC 12763 (AY898252.1), F. oxysporum ATCC MYA-3970 (FJ614642.1), F. solani ATCC MYA-4552 (FJ914886.1), F. proliferatum NRRL:13569 (GQ167231.1), F. verticillioides (FVU34555), Gibberella fujikuroi ATCC 52539 (AY898249.1), G. moniliformis (EF453174.1), and Rhizoctonia solani ATCC MYA-4649 (HQ263348.1) as an external group. All new sequences were submitted to GenBank (accession numbers KM005079-KM005088).

Pathogenic variation assays. On leaves - Healthy vanilla leaves of the same plant were collected and washed with a liquid soap solution and disinfected with $2 \%$ sodium hypochlorite (v/v) for $2 \mathrm{~min}$. The leaves were then rinsed twice with sterile distilled water.

To evaluate the pathogenic variation among the 11 isolates on vanilla leaves, a random design was established and repeated five times, and each test was performed twice. For this process, an $\sim 5$-mm-diameter fragment of each colony from each isolate was placed on each leaf and incubated in PDA medium for ten days at $25 \pm 1^{\circ} \mathrm{C}$. Healthy vanilla leaves with a fragment of PDA free of microorganisms were employed as a control. The leaves were incubated in a damp chamber ( $100 \%$ relative humidity) at $25 \pm 1{ }^{\circ} \mathrm{C}$ for 12 days, and four levels of damage were determined: (1) leaves with no symptoms, (2) leaves with chlorosis, (3) leaves with rot, and (4) leaves showing necrosis or dead leaves.

Lesions that developed on symptomatic plants were excised and rinsed in sterile distilled water before plating on PDA. The plates were incubated as described above, and colonies developing from the leaf sections were purified and morphologically and molecularly identified as described above. Re-isolation of the fungus that was used for inoculation was taken as confirmation of Koch's Postulates.

On rooted stems - The treatments were established in black bags $(10 \times 15 \mathrm{~cm})$ with $500 \mathrm{~g}$ of soil inoculated with $10 \mathrm{~mL}$ of Fusarium spp. spore suspension $\left(10^{6}\right.$ spores $\left.\mathrm{mL}^{-1}\right)$ after 12 days of growth on the PDA medium at $26 \pm 1{ }^{\circ} \mathrm{C}$. An initial suspension of spores was prepared from each strain, and $2 \mathrm{~mL}$ of Tween 20 solution $(20 \%)$ was added to the Petri dish that contained the mycelium. Each suspension of conidia was emptied into test tubes containing $8 \mathrm{~mL}$ of sterile distilled water and mixed using a vortexer (MAXIMIX II). These tubes provided the basis for the preparation of individual suspensions with a concentration of $10^{6} \mathrm{~mL}^{-1}$ spores, as determined by counting in a Neubauer chamber. A control solution was also prepared that contained no fungal inoculate, $2 \mathrm{~mL}$ of Tween $20(20 \%)$ and $8 \mathrm{~mL}$ of sterile distilled water.

To evaluate pathogenic variation, rooted stems $(\sim 30 \mathrm{~cm}$ long) with 2 knots were used. The stems were planted two days after inoculating the soil with the fungus. A few moments before planting, a 1-cm incision was made in the portion of the stem that was in contact with the soil using a sterile blade. The stems were watered three times a week, and the temperature of the greenhouse oscillated between 26- $28^{\circ} \mathrm{C}$ during the day and between $22-24{ }^{\circ} \mathrm{C}$ at night.

The assay was established in randomized blocks, with five repetitions where the 11 isolates of Fusarium were evaluated; the test was repeated twice. The level of damage to the stems was evaluated after 60 days, and four levels of damage could be observed: (1) cutting with no symptoms, (2) cutting with chlorosis, (3) cutting with rot, and (4) cutting with necrosis or dead stems. Koch's Postulates were 
applied to confirm the presence of the inoculated fungus, as described above.

The data obtained from these pathogenic tests (leaves and stems) were analyzed using non-parametric Friedman ANOVA and Kendall's coefficient of concordance analysis. To carry out the non-parametric analysis, a Wilcoxon test was applied. All statistical procedures were performed using the Statistica software (version 7.0).

\section{Results}

Identification of Fusarium spp. One hundred and eightynine isolates of Fusarium spp. were collected from the damaged vanilla plant tissues and classified into 11 groups according to the differences observed during their mycelial development (color, form and diameter). Once the isolates were classified, they were observed for variability in the microscopic characteristics of their conidia. Based on the foregoing classifications, the isolates of this study were identified as $F$. proliferatum (group HJAG1), F. oxysporum f. sp. vanillae (HJAG2, HJAG3, HJAG4, HJAG5, HJAG7, HJAG8, HJAG9, HJAG10 and HJAG11) and Fusarium sp. (HJAG6).

The isolates of Fusarium oxysporum produced colonies that were white or violet in color and with areal mycelia and a cottony or fibrous texture. The coloring of the surface of the colonies varied from pink to light or dark violet (Figure 1A, B, C). The microconidia formed false heads in short monophiliades (Figure 1D) and abundant uni-bicellular microconidia formed that were oval or elliptical. The macroconidia appeared with 3-5 septa in the form of a canoe, with a large apical cell and base cells in the form of a foot (Figure 1E). The chlamydospores appeared to be single and were rarely observed in pairs in cultures after three weeks on CLA medium (Figure 1F).

Abundant aerial mycelia were observed in the Fusarium proliferatum isolates that were initially white in color and later changed to violet-purple (Figure 2A). Monophialides and polyphialides with conidia in chain formation and at the head were observed. The macroconidia had 1-3 septa, a slightly curved apical cell and a scarcely developed base cell (Figure 2B). The microconidia were oval in form, with a flat base and no septa (Figure 2C). No chlamydospores were observed.

According to the morphological characteristics, it was not possible to identify isolates of the third group at the species level. On culture medium, the presence of white to pale yellow mycelia was reported (Figure 3A), and monophialides with no branches on false heads as well as abundant macroconidia with three septa were observed, although some had four or five septa (Figure 3B). The apical cell was slightly curved, and the base cell displayed the form of a
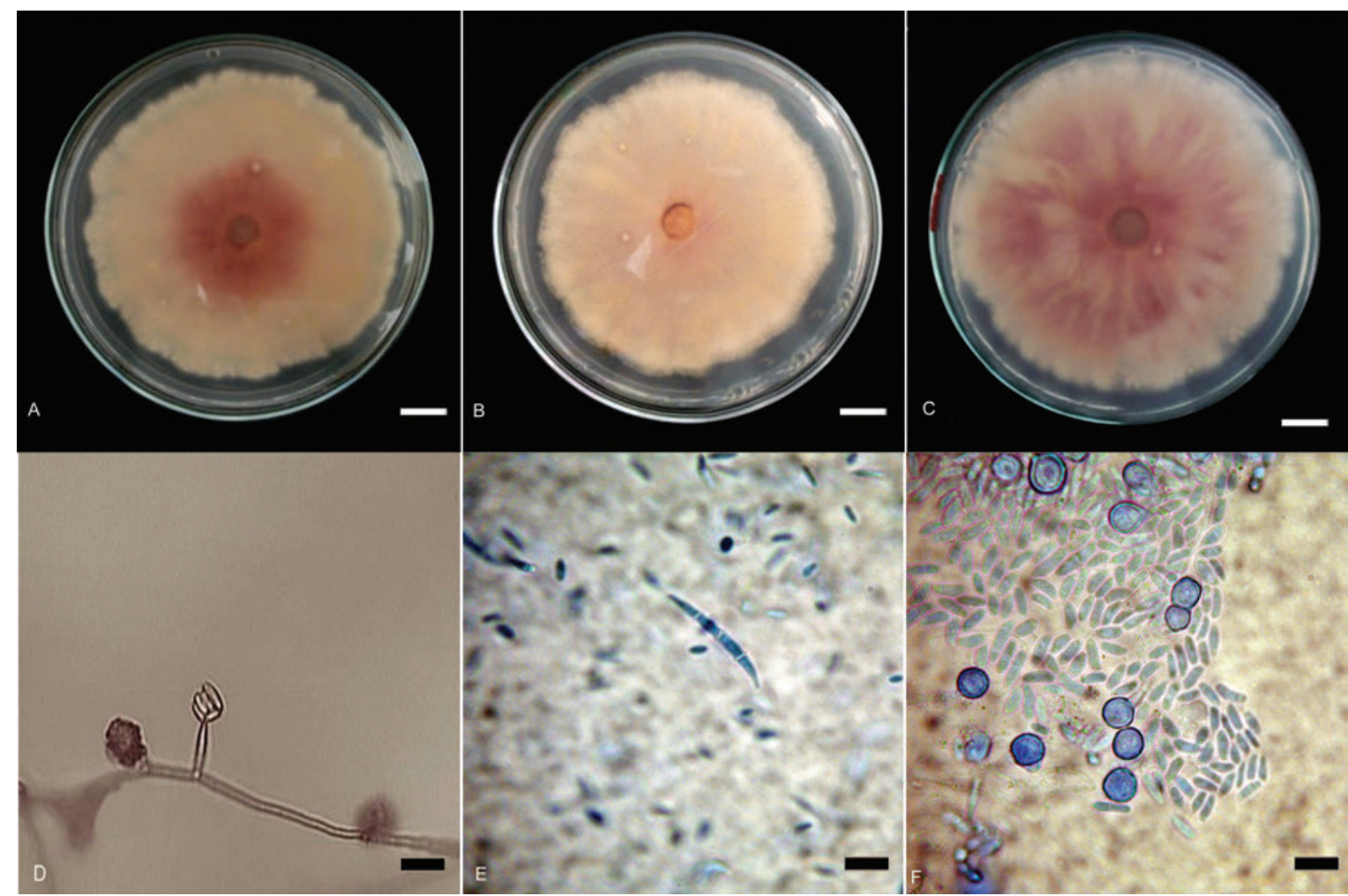

Figure 1. A-C) Mycelia of isolates identified as Fusarium oxysporum developed in PDA culture medium, D) False head, E) macroconidia and F) microconidia and chlamydospores. Bar: A-C $=10 \mathrm{~mm} ; \mathrm{D}=50 \mu \mathrm{m} ; \mathrm{E}-\mathrm{F}=10 \mu \mathrm{m}$. 

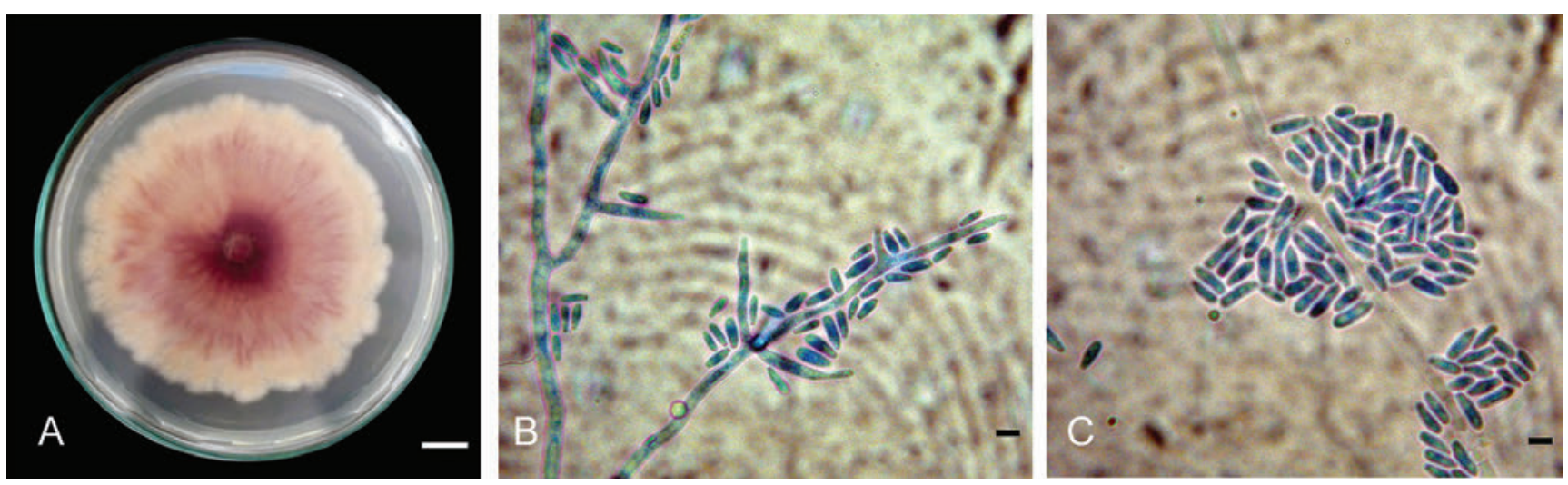

Figure 2. A) Mycelia corresponding to isolates identified as Fusarium proliferatum that were developed on PDA culture medium, B) monophialides and C) microconidia. Bar: A = $10 \mathrm{~mm} ; \mathrm{B}-\mathrm{C}=10 \mu \mathrm{m}$.

foot. The presence of abundant oval or elliptically shaped microconidia with no or few septa was also observed. No chlamydospores were observed (Figure 3C).

To confirm the morphological identification of the 11 studied strains, molecular analyses were performed. Amplification of the ITS fragment of the isolates generated a product of $\sim 600$ bp (GenBank accession numbers KM005079, KM005080, KM005081, KM005082, KM005083, KM005084, KM005085, KM005086, KM005087and KM005088), which presented a similar score in more than $90 \%$ of the cases with regard to Gibberella moniliformis, $F$. oxysporum, F. proliferatum, and Fusarium sp. when comparing the sequences using BLAST analysis.

The results of the dendrograms obtained by the Maximum Parsimony (MP) algorithm and Maximum Likelihood method were similar, which indicated that the strains of Fusarium spp. were grouped into three clades. In the first were eight strains that morphologically corresponded to F. oxysporum and specifically grouped with $F$. oxysporum $\mathrm{f}$. sp. vanillae DL-1-1 and ML-1-1, as reported by Wang et al. (2003). A second group was formed by the Fusarium sp. (HJAG6) strain, and the organisms corresponded to the Gibberella fujikuroi complex. The third clade grouped the HJAG1 strain with $F$. proliferatum according to its morphological description (Figure 4).

Pathogenic assays. On leaves - The results revealed significant differences $(\mathrm{df}=11, P<0.001)$ in the pathogenic capacity of the isolates. Two Fusarium isolates provided highly pathogenic $F$. oxysporum f. sp. vanillae (HJAG2 and HJAG9) that caused a high level of damage $(3=$ rot and $4=$ tissue death) (Figure 5). Of these, the HJAG2 isolate had the highest level of pathogenic variation $(\mathrm{df}=11, P=0.0431)$ (Figure 6A). The Fusarium sp. HJAG6 and $F$. oxysporum $\mathrm{f}$. sp. vanillae HJAG7, HJAG8, HJAG10, and HJAG11 isolates showed moderate levels of pathogenic variation, producing tissue chlorosis and small areas of rot. No significant differences in pathogenic variation were visible among these isolates. The $F$. proliferatum (HJAG1) and $F$. oxysporum $\mathrm{f}$. sp. vanillae (HJAG5) isolates did not cause any damage to vanilla leaves and were considered non-pathogenic isolates (Figure 6A).
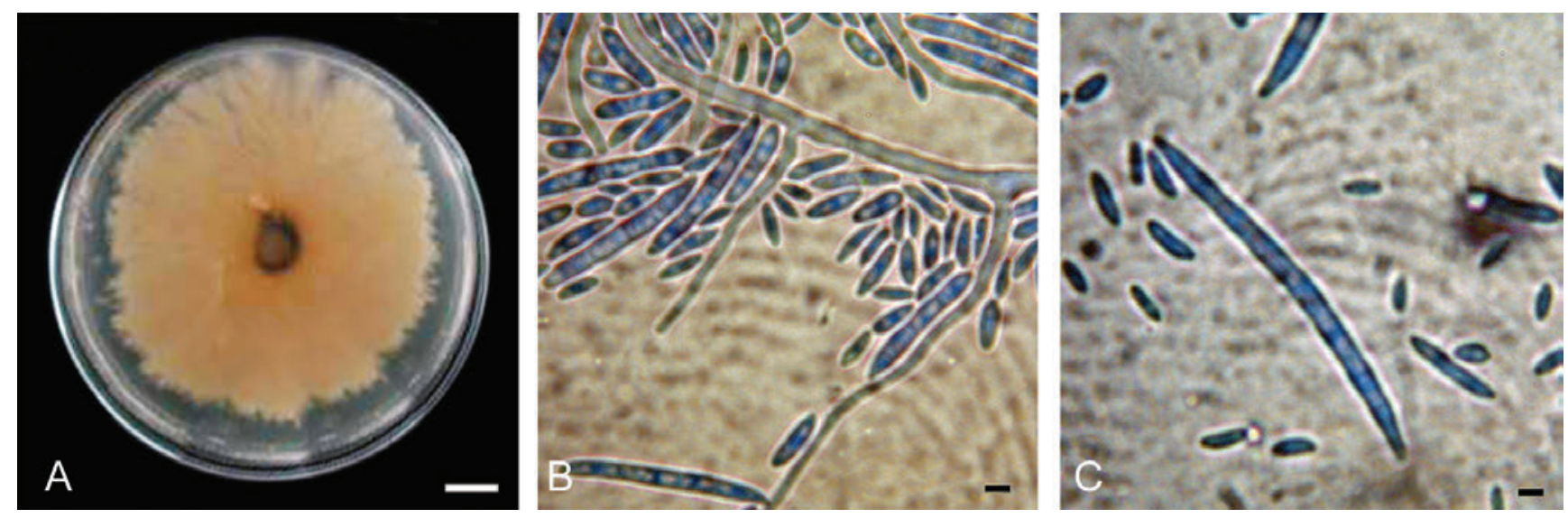

Figure 3. A) Mycelia from isolates of Fusarium sp. on PDA culture medium, B) monophialides and macroconidia, C) macroconidia and microconidia. Bar: $\mathrm{A}=10 \mathrm{~mm}$; $\mathrm{B}-\mathrm{C}=10 \mu \mathrm{m}$. 


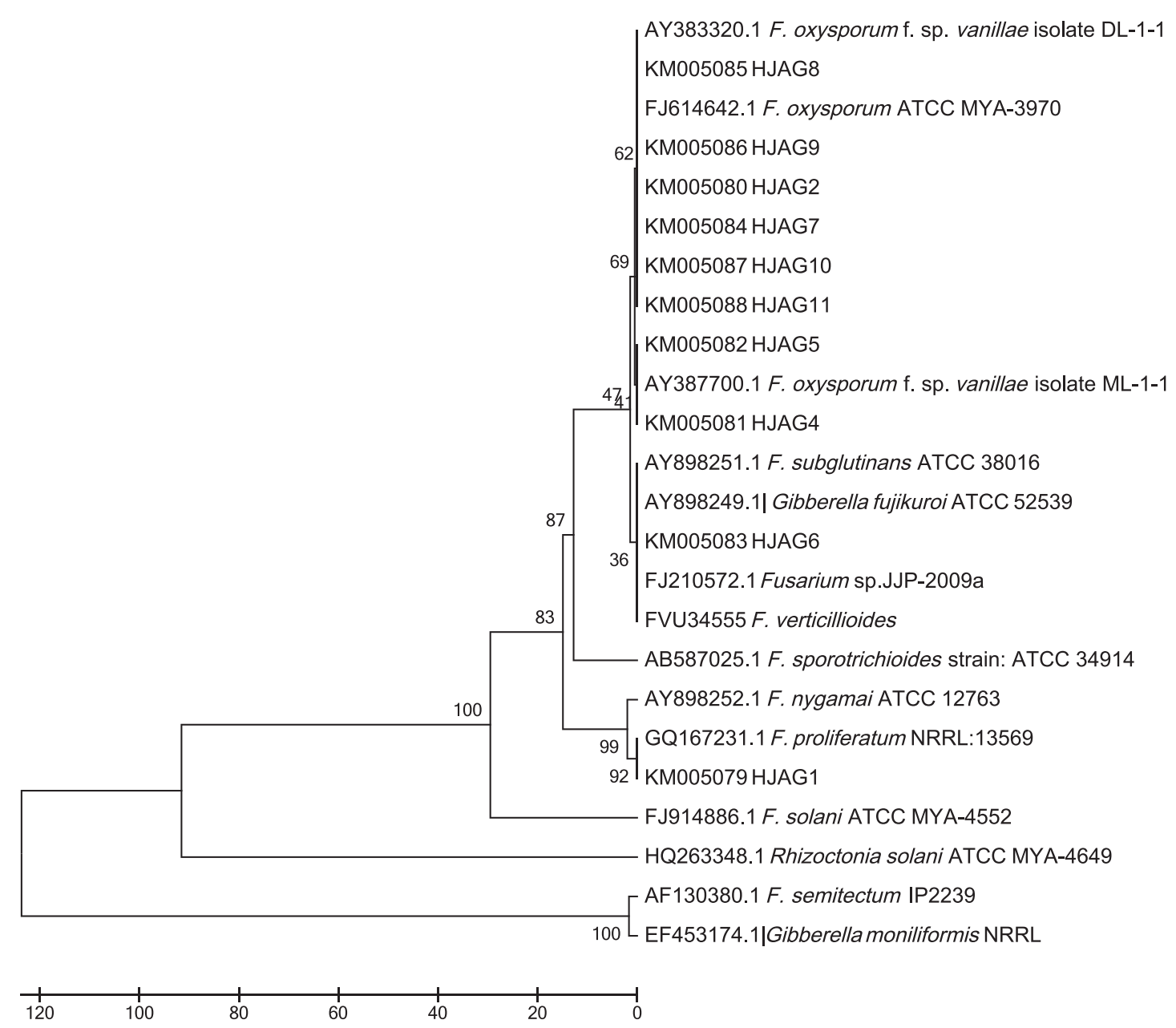

Figure 4. Maximum parsimony analysis inferred by the ITS sequence. The bootstrap values are indicated as percentages above the nodes in this analysis (10,000 replicates). The GenBank accession number precedes the name of the species. NRRL (Agricultural Research Service Culture Collection, USDA), ATCC (American Type Collection, USA).

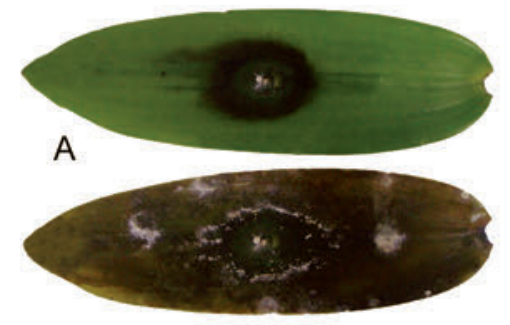

B

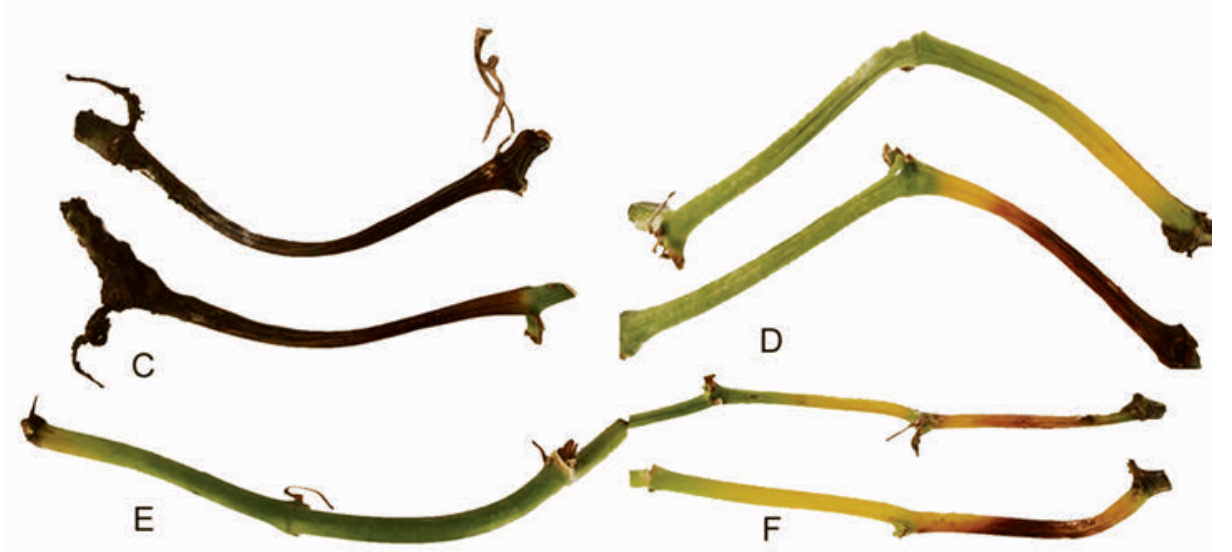

Figure 5. Damage produced by the Fusarium oxysporum f. sp. vanillae (HJAG2) isolate on vanilla leaves A) after 5 days and B) after 12 days of inoculation. Damage caused by Fusarium spp. isolates on vanilla stems: C) F. oxysporum f. sp. vanilla HJAG2, D) F. oxysporum f. sp. vanilla HJAG5, E) Fusarium proliferatum, and F) F. oxysporum f. sp. vanilla HJAG8. 

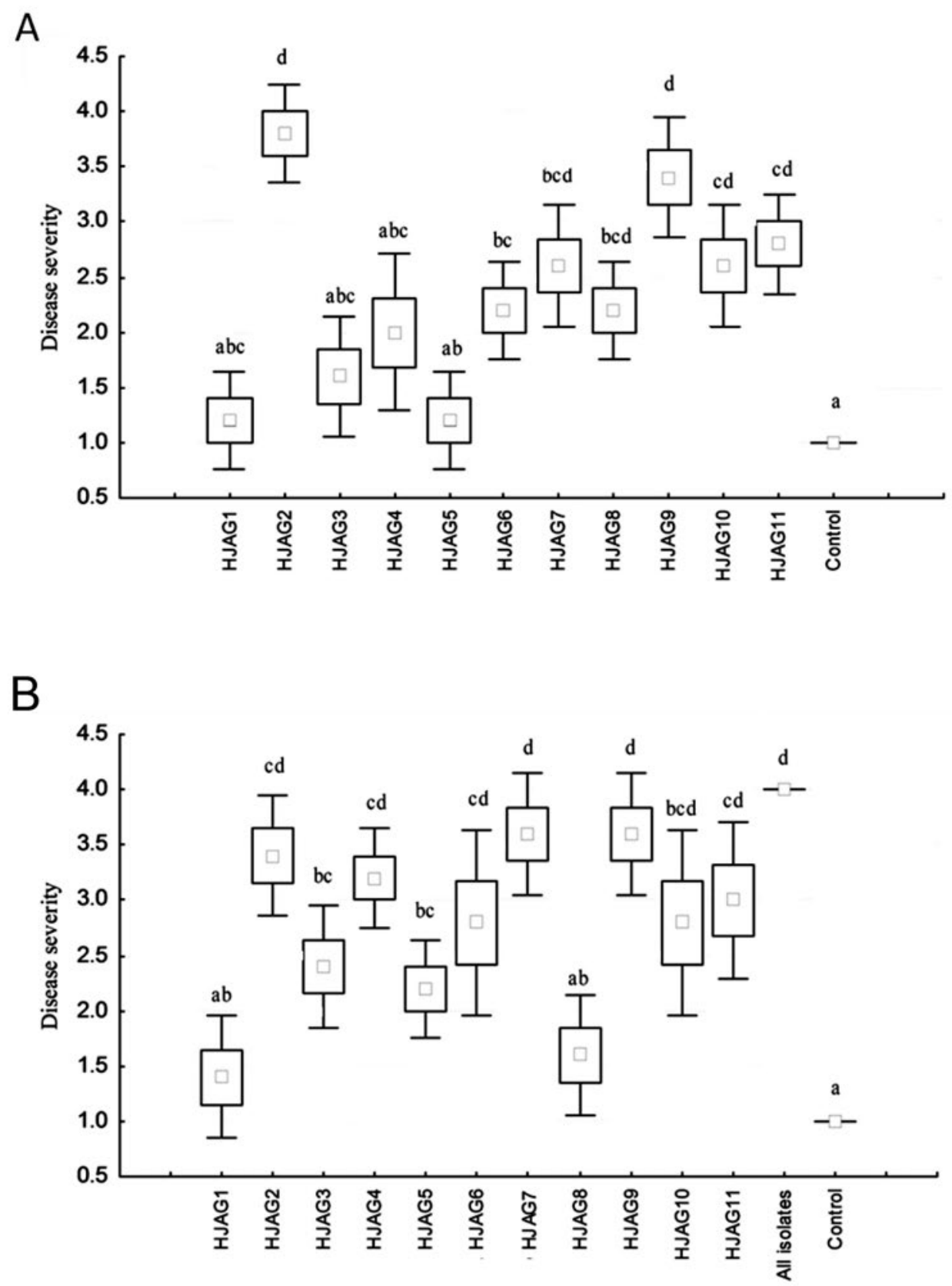

Figure 6. Variation in the pathogenic capacity of Fusarium spp. isolates on vanilla leaves after 12 days of inoculation (A) and on vanilla stems after 20 days of inoculation (B). Fusarium proliferatum (HJAG1), Fusarium oxysporum f. sp. vanillae (HJAG2, HJAG3, HJAG4, HJAG5, HJAG7, HJAG8, HJAG9, HJAG10 and HJAG11) and Fusarium sp. (HJAG6). Different letters indicate significant differences (Wilcoxon, $P<0.05$ ).

On stems - These results also revealed significant differences (df $=12, P<0.001)$ (Figure 6B). The Fusarium proliferatum $\mathrm{HJAG} 1$ isolate did not manifest any disease symptoms on stems or leaves (Figure 5E). However, $F$. oxysporum f. sp. vanillae HJAG8, which had a moderate pathogenic effect on leaves, was not considered pathogenic to stems (Figure 5F). These isolates did not manifest any significant differences with regard to the control (Figure 6).
Contrary to the results observed for leaves, the HJAG5 (Fusarium oxysporum f. sp. vanillae) isolate showed moderate pathogenic activity because it provoked symptoms of chlorosis and, on some parts of the stem, tissue rot (Figure 5D). The HJAG3 isolate behaved in a similar manner as the same species of fungus, and the HJAG2 and HJAG9 (F. oxysporum f. sp. vanillae) isolates behaved in a similar manner, with vanilla leaves providing one of the more active pathogenic isolates (Figure 5C). The HJAG10 and HJAG11 
Table 1. Basic Local Alignment Search Tool (BLAST) analysis results.

\begin{tabular}{|c|c|c|c|}
\hline Description & Ident & Query cover & E value \\
\hline Gibberella moniliformis NRRL, ITS1, 5.8S rRNA, ITS2, partial and complete sequence. & $99 \%$ & $100 \%$ & 0.0 \\
\hline $\begin{array}{l}\text { Fusarium oxysporum ATCC MYA-3970, ITS1, 5.8S rRNA, ITS2, 28S rRNA, partial and } \\
\text { complete sequence }\end{array}$ & $98 \%$ & $97 \%$ & 0.0 \\
\hline $\begin{array}{l}\text { Gibberella fujikuroi ATCC } 52539 \text { genes for } 18 \mathrm{~S} \text { rRNA, ITS1, 5.8S rRNA, ITS2, } 28 \mathrm{~S} \text { rRNA, } \\
\text { partial and complete sequence }\end{array}$ & $98 \%$ & $98 \%$ & 0.0 \\
\hline $\begin{array}{l}\text { Fusarium proliferatum NRRL:13569, 18S ribosomal RNA, ITS 1, 5.8S ribosomal RNA } \\
\text { gene, and ITS } 2\end{array}$ & $99 \%$ & $98 \%$ & 0.0 \\
\hline $\begin{array}{l}\text { Fusarium oxysporum f. sp. vanillae DL-1-1 ITS1, partial sequence; } 5.8 \mathrm{~S} \text { ribosomal } \\
\text { RNA gene, complete sequence; and ITS 2, partial sequence }\end{array}$ & $99 \%$ & $97 \%$ & 0.0 \\
\hline $\begin{array}{l}\text { Fusarium verticillioides strain HPA3 } 18 \text { S ribosomal RNA gene, partial sequence; ITS } 1 \text {, } \\
5.8 \text { S ribosomal RNA gene, and ITS 2, complete sequence }\end{array}$ & $99 \%$ & $100 \%$ & 0.0 \\
\hline Fusarium sp. ITS 1, 5.8S ribosomal RNA gene, and ITS 2, complete sequence & $99 \%$ & $100 \%$ & 0.0 \\
\hline $\begin{array}{l}\text { Fusarium fujikuroi } 18 \mathrm{~S} \text { ribosomal RNA gene, ITS 1, } 5.8 \mathrm{~S} \text { ribosomal RNA gene, } \\
\text { and ITS 2, complete sequence }\end{array}$ & $99 \%$ & $100 \%$ & 0.0 \\
\hline
\end{tabular}

isolates followed, with both corresponding to $F$. oxysporum f. sp. vanillae, while HJAG6 (Fusarium sp.), HJAG4 and HJAG7 (F. oxysporum f. sp. vanillae) increased their level of pathogenic variation on stems, where they induced symptoms of tissue rot, yet these isolates only developed chlorosis on leaves. When plant tissues were inoculated with a mixture of the eleven isolates, a greater level of damage was observed on the inoculated stems, leading to wilting and death (Figure 6).

\section{Discussion}

Fusarium oxysporum f. sp. vanillae was associated with rot disease on stems and roots of vanilla plants in the present study. These results are in accordance with those of Tombe et al. (1993), who morphologically identified 100 isolates of Fusarium on damaged vanilla tissues and concluded that all isolates belonged to the $F$. oxysporum species. However, the authors did not mention the presence of other Fusarium species, as was reported by Pinaria et al. (2010), who isolated twelve species of Fusarium from damaged vanilla tissues, with $F$. oxysporum, $F$. semitectum, and $F$. solani being the most predominant.

Similar to the results of Pinaria et al. (2010), the majority of isolates in this study corresponded to Fusarium oxysporum f. sp. vanillae, and only a few corresponded to other species, such as $F$. proliferatum. The morphological characteristics of the colonies of these species on PDA media were similar. To differentiate them, it was necessary to evaluate the presence of microconidia in chain formation for $F$. proliferatum and the presence of chlamydospores and microconidia on false heads for $F$. oxysporum f. sp. vanillae when cultivated on SNA and CLA media (Leslie and Summerell, 2006).

The results suggested that the HJAG6 isolate, which could not be identified taxonomically using a combination of morphological and molecular characteristics, was similar to the Gibberella fujikuroi complex, Fusarium subglutinans and $F$. verticillioides. To achieve greater precision, further molecular studies are required (O'Donnell et al., 1998).

According to these authors, nuclear (EF1 $\alpha)$ and mitochondrial (mtSSU rDNA) gene sequences are excellent phylogenic markers for resolving problems within the $F u$ sarium oxysporum complex. In addition, the use of the EF1 $\alpha$ gene sequence has demonstrated the capacity to corroborate species identity within the Gibberella fujikuroi complex.

The moderate pathogenicity of the HJAG6 strain was underlined due to the chlorosis and stem rot it generated on vanilla leaves. The differences in the results of the pathogenic variation tests exhibited by the various strains of Fusarium spp. coincided with those reported by AdameGarcía et al. (2011), who observed strong morphological and pathogenic variability as well as a high degree of polymorphism in esterases among the fungi that cause stem rot in Vanilla planifolia.

Based on the high degree of pathogenic variation shown on leaves and stems, two isolates of Fusarium oxysporum $\mathrm{f}$. sp. vanillae (HJAG2 and HJAG9) were classified as highly pathogenic. These results coincide with those reported by Tombe et al. (1993) and Pinaria et al. (2010) in Indonesia, as all of the obtained $F$. oxysporum isolates were observed to be pathogenic on vanilla, although neither report specified the degree of damage.

The HJAG7, HJAG10 and HJAG11 isolates that were also identified as Fusarium oxysporum f. sp. vanillae showed moderate pathogenic activity because they did not cause the death of any tissue, only chlorosis and, in some cases, small areas of rot. The HJAG5 (F. oxysporum f. sp. vanillae) isolate exhibited special pathogenic behavior, as it did not develop any disease on the leaves and only had a moderate effect on stems, where it produced symptoms of 
tissue chlorosis and rot in limited areas. In this regard, no reports of similar work on vanilla have been found.

It is important to underline that variable pathogenic activity was found for Fusarium oxysporum f. sp. vanillae isolates, as they demonstrated differences in the severity of damage to each inoculated tissue and among the vegetative tissues that were used. Given these results, further study is needed to widen the knowledge of the pathogenicity of this species to provide an adequate interpretation of its behavior. According to Summerell et al. (2011), this pathogenic variation has not been tested or compared with its vegetative compatibility nor have any molecular analyses with other known members been carried out.

Further developments using this type of study will contribute towards obtaining information such as that obtained for Fusarium oxysporum f. sp. cubense, the agent causing Panama disease. Koenig et al. (1997), while studying restriction fragment length polymorphisms (RFLPs) in a global collection of $F$. oxysporum $\mathrm{f}$. sp. cubense, discovered that this organism might be closely related to those from other hosts, such as tomato. However, O’Donnell et al. (1998) mentioned that fungal agents whose evolutionary origins are independent of other special forms that attack other hosts cause Panama disease.

Another species obtained in this study was Fusarium proliferatum, which caused no damage to vanilla tissues (leaves or stems) and is therefore considered to be non-pathogenic. Pinaria et al. (2010) indicated that this species is less common (found with a frequency of less than $3 \%$ ) and is not pathogenic to vanilla, but it is considered to be a saprophytic species or endophytic colonizer of vanilla in Indonesia. F. proliferatum is often isolated as a saprophyte on various parts (roots and stem base) of diseased plants and is reported as pathogenic to crops such as maize (Leslie and Summerell, 2006).

The results obtained from the present study offer valuable information on the association of Fusarium species with stem and root rot of vanilla in Mexico. These results, together with studies that are currently in progress, contribute towards a better understanding of the etiology of this disease and open possibilities for future investigations related to its control.

\section{Acknowledgements}

To the Consejo Nacional de Ciencia y Tecnología (CONACyT) and Tecnológico Nacional de México (TecNM) for providing a grant (27314) and license for a grant study assigned to the first author for her doctoral studies at the Instituto de Biotecnología y Ecología Aplicada (INBIOTECA) of the Universidad Veracruzana, to Pablo Octavio Aguilar for his support and suggestions on the methods employed in the statistical analysis, two anonymous reviewers and the editorial staff provided helpful comments that improved our manuscript.

\section{Literature cited}

Adame-García J., Trigos-Landa Á.R., Iglesias-Andreu L.G., Flores-Estevez N. and Luna-Rodríguez M. 2011. Isozymic and pathogenic variations of Fusarium spp. associated with vanilla stem and root rotting. Tropical and Subtropical Agroecosystems 13:299-306.

Alconero R. and Santiago A.G. 1969. Fusaria pathogenic to vanilla. Plant Disease Reporter 53:854-857.

Bhai R.S. and Kumar A. 2008. Effect of rhizobacteria on Phytophtora meadii, Fusarium oxysporum f. sp. vanillae and Colletotrichum vanillae infecting vanilla. Journal of Biological Control 22:33-41.

Bhai R.S. and Thomas J. 2000. Phytophthora rot-a new disease of vanilla (Vanilla planifolia Andrews) in India. Journal of Spices and Aromatic Crops 9:73-75.

Cheng H.R. and Jiang N. 2006. Extremely rapid extraction of DNA from bacteria and yeasts. Biotechnology Letters 28:55-59.

Felsenstein J. 1985. Confidence limits on phylogenies: An approach using the bootstrap. Evolution 39:783-791.

Geiser D., Jiménez-Gasco M., Kang S., Makalowska I., Veeraraghavan N., Ward T., Zhang N., Kuldau G. and O'Donnell K. 2004. FUSARIUM-ID v. 1.0: A DNA sequence database for identifying Fusarium. European Journal of Plant Pathology 110:473-479.

Guzman C.C. 2004. Vanilla. In: Peter K.V. Ed. Handbook of Herbs and Spices, pp. 322-349, Woodhead Publishing, England.

Hall T.A. 1999. BioEdit: a user-friendly biological sequence alignment editor and analysis program for Windows 95/98/NT. Nucleid Acids Symposium Series 41:95-98.

Koenig R.L., Ploetz R.C. and Kistler H.C. 1997. Fusarium oxysporum f. sp. cubense consists of a small number of divergent and globally distributed clonal lineages. Phytopatology 87:915-923.

Leslie J.F. and Summerell B.A. 2006. The Fusarium Laboratory Manual. Blackwell Publications, Iowa.

Lima D.M.M. 1991. Preservacao de espécies de Fusarium sob óleo mineral. Pesquisa Agropecuária Brasileira 26:853-855.

Minoo D., Jayakumar V.N., Veena S.S., Vimala J., Basha A., Saji K.V., Babu K.N. and Peter K.V.2008. Genetic variations and interrelationships in Vanilla planifolia and few related species as expressed by RAPD polymorphism. Genetic Resources and Crop Evolution 55:459-470.

Montiel-González L., González-Flores F., Sánchez-García B.M., Guzmán-Rivera S., Gámez-Vázquez F.P., Acosta-Gallegos J.A., Rodríguez-Guerra R., Simpson-Williamson W.J., CabralEnciso M. and Mendoza-Elos M. 2005. Especies de Fusarium presentes en raíces de frijol (Phaseolus vulgaris L.) con daños de pudrición, en cinco estados del centro de México. Revista Mexicana de Fitopatología 23:1-7.

Nei M. and Kumar S. 2000. Molecular Evolution and Phylogenetics. Oxford University Press.

Nelson P.E., Toussoun T.A. and Marasas W.F.O. 1983. Fusarium species: An Illustrated Manual for Identification. Pennsylvania State University Press.

O’Donnell K., Kistler H.C., Cigelnik E. and Ploetz R.C. 1998. Multiple evolutionary origins of the fungus causing Panama disease of banana: Concordant evidence from nuclear and mitochondrial gene genealogies. Proceedings of the National Academy of Sciences 95:2044-2049. 
Pinaria A.G., Liew E.C.Y. and Burgess L.W. 2010. Fusarium species associated with vanilla stem rot in Indonesia. Australasian Plant Pathology 39:176-183.

Summerell B.A., Leslie J.F., Liew E.C.Y., Laurence M.H., Bullock S., Petrovic T., Bentley A.R., Howard C.G., Peterson S.A., Walsh J.L. and Burgess L.W. 2011. Fusarium species associated with plants in Australia. Fungal Diversity 46:1-27.

Summerell B.A., Salleh B. and Leslie J.F. 2003. A utilitarian approach to Fusarium identification. Plant Disease 87:117-128.

Talubnak C. and Soytong K. 2010. Biological control of vanilla anthracnose using Emericella nidulans. Journal of Agricultural Technology 6:47-55.

Tamura K. and Nei M. 1993. Estimation of the number of nucleotide substitutions in the control region of mitochondrial DNA in humans and chimpanzees. Molecular Biology and Evolution 10:512-526.

Tamura K., Peterson D., Peterson N., Stecher G., Nei M. and Ku- mar S. 2011. MEGA5: Molecular evolutionary genetics analysis using maximum likelihood, evolutionary distance, and maximum parsimony methods. Molecular Biology and Evolution 28:2731-2739.

Tombe M., Komoto Y. and Tezuka N. 1993. Identification and cultural types of Fusarium isolates from Vanilla in Indonesia. Industrial Crop Research Journal 6:1-5.

Tucker C.M. 1927. Vanilla root rot. Journal of Agricultural Research 35:1121-1136.

Vilgalys R. and Hester M. 1990. Rapid genetic identification and mapping of enzymatically amplified ribosomal DNA from several Cryptococcus species. Journal of Bacteriology 172:42384246.

Wang Y.Y., Whitehead M., Zhu Y., Burns A., Hocking T., Ruan X.Y. and Kong Q. 2003. Fusarium oxysporum f. sp. vanillae isolate DL-1-1 ITS1, 5.8SrDNA, ITS 2 sequence. Dept. Plant Pathology, Yunnan Agricultural University.

Received: May 8th, 2014

Accepted: August 19th, 2014 